\title{
Cannabidiol as a Treatment for Chronic Pain: A Survey of Patients' Perspectives and Attitudes
}

\author{
Jan M Schilling (D) \\ Chloe G Hughes' \\ Mark S Wallace ${ }^{2}$ \\ Michelle Sexton (iD ${ }^{2}$ \\ Miroslav Backonjal,3 \\ Tobias Moeller-Bertram' \\ 'Clinical Research, Vitamed Research, \\ Palm Desert, CA, USA; ${ }^{2}$ Department of \\ Anesthesiology, University of California \\ San Diego, San Diego, CA, USA; \\ ${ }^{3}$ Department of Neurology, University of \\ Washington, Seattle, WA, USA
}

Correspondence: Jan M Schilling; Tobias Moeller-Bertram Clinical Research, Vitamed Research, LLC, 44630 Monterey Ave, Suite 100, Palm Desert, CA, 92260, USA

Email jan@vitamedresearch.com; toby@vitamedresearch.com

\begin{abstract}
Introduction: Cannabis products have become easily available and accessible after decriminalization of cannabis for recreational and medicinal use in many states. Cannabidiol (CBD) has been of increasing interest to patients and is being used to self-medicate a variety of ailments. However, very limited information is available to patients and providers to form an educated opinion regarding its indicated use to treat the many conditions this substance has been implied to be helpful for. The aim of this survey was to learn about participants' attitudes and views towards cannabis-based medicine (CBM) with a focus on perception of "CBD" and its potential role for pain management.
\end{abstract}

Materials and Methods: We recruited survey participants from seven pain management clinics in Southern California to learn about their knowledge, beliefs, and personal experience with CBD products. After Institutional Review Board (IRB) review, an internet survey platform was utilized to administer the survey online.

Results: A total of 253 participants answered the survey. Participants were $45.4 \pm 13.8$ (Mean $\pm \mathrm{SD}$ ) years of age, the majority identified as white $(56.1 \%)$, had an annual household income of less than $\$ 20,000$, and were primarily insured by Medicare (22.5\%) or Medicaid (43.9\%). Among participants, $62.0 \%$ reported trying a CBD product [including products containing delta-9-tetrahydrocannabinol (THC)]. The majority responded that these products have helped their pain $(59.0 \%)$ and allowed them to reduce their pain medications $(67.6 \%)$, including opioids (53.7\%). They reported believing that CBD was a good treatment option (71.1\%), not harmful (74.9\%), and not addictive (65.3\%). About half of participants $(51.9 \%)$ report that they would be more comfortable with their physician prescribing CBD products. The overall attitude and experience of participants regarding CBD is reported as positive, while $91.9 \%$ of people expressed a desire to learn more about it.

Summary: In summary, most participants expressed a positive attitude about CBD products as a treatment option, reported positive outcomes when used for multiple different conditions, and would prefer to obtain information about and prescription for CBD from their physicians.

Keywords: survey, cannabidiol, CBD, medical marijuana, cannabis

\section{Introduction}

Public demand for the legalization of cannabis resulted in legalization of medical cannabis in the United States first in California in $1996 .{ }^{1}$ As of December 2020, thirtysix states and 4 territories have legalized the use of marijuana for medical purposes, creating a new treatment option for patients seeking alternative therapies. Perceived health benefits have been reported in mainstream and social media like eg, pinterest. ${ }^{2}$ Unfortunately, this growing body of information around cannabis-based medications, specifically CBD and related health benefit claims, is not based on sound scientific 
research in the vast majority of cases. To further complicate the picture, cannabis-based medications including CBD products are poorly regulated in terms of their production and testing, vary in purity and consistency, and are often mislabeled. $^{3}$ As a result, the consumer of cannabis-based medications including CBD often cannot be sure about the actual quality and content of the products they consume.

Fortunately, the scientific interest in cannabinoid research has increased in recent years. ${ }^{4}$ In particular, there has been a focus on the phytocannabinoid cannabidiol (CBD) ${ }^{5,6}$ However, the evidence available is inconclusive at best, and this emphasizes the need for scientifically valid information about this compound. ${ }^{7}$

A PubMed search revealed that the number of published research studies investigating the effects of CBD has more than doubled since the year 2016. CBD has been investigated as a treatment for childhood epilepsy, ${ }^{8,9}$ reviewed as a potential treatment for chronic pain, ${ }^{10-13}$ and some studies suggest usefulness to treat anxiety disorders. ${ }^{14-16}$ There is ongoing research about whether the legalization of cannabis products affects opioid use and abuse. Recent studies have discovered a negative correlation between opioid use and cannabis laws ${ }^{17}$ and have suggested that cannabis products might decrease use of opioid medications and the associated risks. ${ }^{17-22}$

Taken together, the consumer of CBD products faces a landscape in which there is budding scientific evidence of beneficial effects for several conditions against a background of unproven claims and questionable products on the market. This currently ambiguous situation and somewhat unclear messaging around cannabis-based medications to the public poses the important questions around the current knowledge and believes about these products. Surveyed populations to date include a primary care setting, ${ }^{23}$ young adults ${ }^{24}$ and social media posts. ${ }^{2}$

Given that one leading cause mentioned for CBD consumption is pain, the aim of this study was to assess the knowledge base, beliefs, and personal experience with CBM and CBD products by surveying patients seen at a series of pain management clinics. These results can help to address the gap of patients believes and supported scientific findings around $\mathrm{CBD}$ and aid health care providers in navigating conversations with their patients around these compounds.

\section{Materials and Methods}

Material and Methods are reported according to the checklist for reporting Results of Internet E-surveys (CHERRIES). ${ }^{25}$

\section{Design}

Participants were recruited voluntarily (convenience sample, no incentive) from seven pain clinics in Southern California. Surveys were administered between December 4th 2018 and February 4th 2019.

\section{IRB (Institutional Review Board) Approval and Informed Consent}

The research protocol was reviewed by the Western Institutional Review Board (WIRB) and was determined to be exempt from the requirement of IRB approval meeting the criteria under 45 CFR $\$ 46.101$ (b)(2), including waiver of informed consent. In the specific case of our data collection, the exemption was granted since our research was a voluntary survey, no direct identifiers were collected, and the results will not be submitted to the Food and Drug Administration (FDA) for marketing approval.

\section{Development and Pre-Testing}

The survey (Supplemental Material 1) was designed (JMS, $\mathrm{TMB}, \mathrm{CGH})$ and underwent multiple rounds of internal review and editing by VitaMed Research, LLC. study staff. Our demographic questions were written similar to those being asked in the Census. For our questions about CBD we utilized Yes/No answers, answers on the Likert scale (3-point, 5-point), and some questions with guided answer choices including an "other" option. Following this we entered, reviewed, and tested the questions in the SurveyMonkey environment with several test-runs to eliminate spelling and formatting errors. After this a QR code was created in the software and posters and index cards were distributed in the clinics. This survey is a new survey and has not been utilized prior. The goal of this survey was to collect broad attitudes towards and perception of CBD products to help and guide the generation of new hypothesis.

\section{Recruitment Process and Description of the Sample Having Access to the Questionnaire}

The survey information/link was posted openly in the form of posters, flyers, and business cards containing QR-codes at seven pain clinic locations in Southern California including the University of California, San Diego, Department of Anesthesia Division of Pain Management. Three were locations of Desert Clinic Pain Institute in Riverside County. Three were locations of Summit Institute, two in Riverside County and one in San 
Bernardino County. Both Desert Clinic Pain Institute and Summit Institute are complex pain management clinics who primarily serve Medicare and Medicaid populations. The survey was open to be answered by all patients and staff within our clinics. Additionally, Clinic patients were recruited by clinic staff by direct invitation or by providing business cards during their appointment (Supplemental $\underline{\text { Materials } 2}$ and $\underline{3}$ ).

\section{Survey Administration}

The survey was accessed using a QR code linked to the electronic format. The survey consisted of 32 questions that are presented including their answer choices in Tables 1 and 2 and Supplemental Tables 1 and $\underline{2}$. The survey included questions about the participants demographics (Supplemental Table 1; 12 questions; zip-code data not shown), awareness and efficacy (Table $2 ; 6$ questions), personal experience (Table 3; 7 questions; open-ended item responses were reported verbatim in Supplemental Table 3), and knowledge and beliefs about CBD (Table 3; 7 questions). All questions required an answer before proceeding to the next question, but each question had the option of a neutral answer or "Decline to answer". Since flyers and index cards were publicly available in the clinics, it cannot be excluded that in addition to patients, their family members, friends, or clinic staff participated in the survey. Additionally, theoretically the possibility exists that a responder could have answered the survey more than once. This is prevented by a function of the survey platform that does not allow multiple answers of the survey from the same IP address. However, IP addresses were not collected by us to avoid registering any sort of identifiers. Because of these limitations we cautiously describe our cohort as participants in a pain clinic environment and not as patients.

\section{Data Analysis}

Data was analyzed utilizing IBM SPSS Statistics Subscription software (Build 1.0.0.1298 64-bit edition, IBM, Armonk, NY). Demographics and the results to our questions are presented as descriptive statistics. Pearson's Chi-Square test was utilized for exploratory data analysis in Table 3. The total $N$ and missing answers are shown in each table and the percentage of total (\%) was calculated as percentage of answered questions, unless "Missing" was specified as an answer result. In the Results section, we present the results as the "majority" of answers. The majority was defined as the sum of percent answer choices in one direction excluding the neutral answer choice on the Likert scale. For guided answer choices that included "other", we presented some examples of the most frequently chosen answers. For Yes/No answer choices we presented the answer choice with the most frequent replies. The complete answer choices are listed in the data tables (Tables 1 and 2, Supplemental Tables 1-3).

\section{Results}

A total of 253 participants started the survey and we received between 237 and 253 responses per question with the overall number of responses decreasing towards the end of the survey. Of the 152 participants that answered "yes" to having tried a CBD product, 151 answered the follow-up questions.

Analysis of demographic data (Supplemental Table 1, $N=253$ ) shows that participants were $45.4 \pm 13.8$ (Mean $\pm \mathrm{SD})$ years old, the majority identified as white $(56.1 \%)$, non-Hispanic (51.8\%), had an annual household income of less/equal than $\$ 20,000$ (56.1\%), and received healthcare coverage through Medicare (22.5\%) or Medicaid (43.9\%). Additionally, $36.4 \%$ were unable to work due to disability and $5.1 \%$ of the cohort reported to have served on active duty in the United States armed forces.

Next, we asked the participants questions regarding awareness of CBD (Supplemental Table 2, $N=247$ ). The majority reported knowing someone (family, friend, neighbor) who has used a CBD product $(80.6 \%)$. Additionally, $80.6 \%$ report that somebody they know has previously suggested them to use a CBD product for their pain, while $29.6 \%$ report that their treating providers suggested use of a CBD product for their pain condition. When asked about the perceived efficacy of CBD products, $78.1 \%$ responded that they know somebody who has benefited from using a CBD product for their condition and $7.3 \%$ of participants report that someone they know developed side effects while using a CBD product. When asked if they were interested in learning more about the use of CBD to treat medical conditions, 91.9\% replied with "yes".

When asked if they have tried a CBD product, (Table $1, N=151-247), 152(62.0 \%)$ participants replied that they have tried a CBD product, and $56.3 \%$ report that the CBD product they have used contained tetrahydrocannabinol (THC). When asked if the CBD product helped their condition, participants responded "A lot" (39.1\%), or "Completely" (19.9\%). When asked about what conditions the $\mathrm{CBD}$ products have helped with the most frequently reported conditions were back pain $(67.3 \%)$, nerve pain 
Table I Personal Experience

\begin{tabular}{|c|c|}
\hline \multicolumn{2}{|c|}{ Have you tried a CBD product?, $N(\%), N=247$} \\
\hline Yes & $152(62.0)$ \\
\hline No & $87(35.5)$ \\
\hline \multicolumn{2}{|c|}{ Do you believe the CBD product has helped your condition?, $N(\%), N=151$} \\
\hline Not at all & $\mathrm{I}(0.7)$ \\
\hline Not really & $13(8.6)$ \\
\hline A little bit & $48(31.8)$ \\
\hline A lot & $59(39.1)$ \\
\hline Completely & $30(19.9)$ \\
\hline \multicolumn{2}{|c|}{$\begin{array}{l}\text { If a CBD product has helped your condition, what type of condition did it help? } \\
\text { Check all that apply. } N(\%), N=150\end{array}$} \\
\hline Back pain & $101(67.3)$ \\
\hline Neck pain & $67(44.7)$ \\
\hline Limb pain & $35(23.3)$ \\
\hline Nerve pain & $70(46.7)$ \\
\hline Fibromyalgia & $31(20.7)$ \\
\hline Migraines & $50(33.3)$ \\
\hline Other (please specify) & $58(38.7)$ \\
\hline \multicolumn{2}{|c|}{ What types of products have you tried? Check all that apply. $N(\%), N=|5|$} \\
\hline Oral tincture & $79(52.3)$ \\
\hline Edible & $82(54.3)$ \\
\hline Capsule/Pills & $34(22.5$ \\
\hline Spray & $26(17.2)$ \\
\hline Cream & $75(49.7)$ \\
\hline Ointment/oil & $75(49.7)$ \\
\hline Inhaled/smoked & $95(62.9)$ \\
\hline Other (please specify) & II (7.3) \\
\hline \multicolumn{2}{|c|}{$\begin{array}{l}\text { Did any of the CBD products you used contain THC (the chemical that gets you } \\
\text { "high")?, } N(\%), N=151\end{array}$} \\
\hline Yes & $85(56.3)$ \\
\hline No & $51(33.8)$ \\
\hline I do not know & $13(8.6)$ \\
\hline Decline to answer & $2(1.3)$ \\
\hline \multicolumn{2}{|c|}{$\begin{array}{l}\text { Please choose the answer that best applies to this statement: I was able to } \\
\text { reduce the amount of pain medication I take by using CBD products. N (\%), } \\
N=15 \mid\end{array}$} \\
\hline Strongly disagree & $6(4.0)$ \\
\hline Disagree & $7(4.6)$ \\
\hline Neither agree nor disagree & $36(23.8)$ \\
\hline Agree & $56(37.1)$ \\
\hline Strongly agree & $46(30.5)$ \\
\hline
\end{tabular}

(Continued)
Table I (Continued).

Please choose the answer that best applies to this statement: I was able to reduce the amount of opioid medication I take by using CBD products. (eg, Percocet, Norco, Morphine, Oxycodone), N (\%), N = I5I

\begin{tabular}{|l|l|}
\hline Strongly disagree & $9(6.0)$ \\
Disagree & $6(4.0)$ \\
Neither agree nor disagree & $55(36.4)$ \\
Agree & $40(26.5)$ \\
Strongly agree & $41(27.2)$ \\
\hline
\end{tabular}

Notes: A majority of participants has tried a CBD product in several different formulations and for several different conditions and believe it has helped. Most participants additionally have used CBD products containing THC. More than $50 \%$ of participants believe they were able to reduce their pain medication (including opioids) by using CBD products. Descriptive data are presented as $N$ and percent replies per question (\%).

(46.7\%), and neck pain (44.7\%). When asked what type of products they have used, the most frequent responses were inhaled/smoked (62.9\%), edibles $(54.3 \%)$, and oral tinctures $(52.3 \%)$. All other conditions and products reported can be viewed in detail in Table 1 and verbatim responses are listed in Supplemental Table 3. When asked if using a CBD product was able to reduce the amount of pain medication in general, the majority agreed $(37.1 \%)$ or strongly agreed (30.5\%). Additionally, participants reported that the CBD product helped to reduce the amount of opioid medication specifically ["Agree" (26.5\%), "Strongly Agree" (27.2\%)]. When this data was analyzed by Pearson's Chi-Square test (Table 2) for perceived differences in pain and more specific opioid medication reduction between products containing either CBD or $\mathrm{CBD} / \mathrm{THC}$, we found no difference between groups $\left[X^{2}\right.$ $=0.31$ for "Able to reduce pain medication"; $X^{2}=0.56$ for "Able to reduce opioid medication"].

To gain further insights regarding knowledge, opinions, and interest we next asked a set of questions to all participants focusing on these topics (Table 3, $N=237-241$ ). We were interested to know whether participants distinguish between medical marijuana and CBD with 63.5\% answering "Yes, there is a difference". We then asked the participants about their knowledge of CBD quantity in the product that they have used. Very similar percentages across possible answers were received pointing towards an overall unfamiliarity regarding knowledge of CBD content in used products. Overall, participants report that CBD is a good treatment option ["Agree" (20.9\%), "Strongly Agree" (50.2\%)], and disagree that CBD is 
Table 2 Comparison Between Products Containing CBD and CBD/THC

\begin{tabular}{|c|c|c|c|c|c|c|c|}
\hline \multirow{3}{*}{ Total $N=136$} & \multicolumn{6}{|c|}{ Did any product you used contain THC? } & \multirow[b]{3}{*}{$\mathbf{x}^{2}$} \\
\hline & \multicolumn{3}{|c|}{$\begin{array}{c}\text { Yes } \\
N=85\end{array}$} & \multicolumn{3}{|c|}{$\begin{array}{c}\text { No } \\
N=5 \text { I }\end{array}$} & \\
\hline & $\mathbf{N}$ & $\begin{array}{c}\text { \% within 'contain } \\
\text { THC' }\end{array}$ & $\begin{array}{c}\% \text { within 'reduce } \\
\text { med' }\end{array}$ & $\mathbf{N}$ & $\begin{array}{c}\text { \% within 'contain } \\
\text { THC' }\end{array}$ & $\begin{array}{c}\% \text { within 'reduce } \\
\text { med' }\end{array}$ & \\
\hline $\begin{array}{l}\text { Able to reduce pain } \\
\text { medication? }\end{array}$ & & & & & & & 0.31 \\
\hline Strongly disagree & 1 & 1.2 & 20.0 & 4 & 7.8 & 80.0 & \\
\hline Disagree & 3 & 3.5 & 50.0 & 3 & 5.9 & 50.0 & \\
\hline $\begin{array}{l}\text { Neither agree nor } \\
\text { disagree }\end{array}$ & 21 & 24.7 & 61.8 & 13 & 25.5 & 38.2 & \\
\hline Agree & 33 & 38.8 & 67.3 & 16 & 31.4 & 32.7 & \\
\hline Strongly agree & 27 & 31.8 & 64.3 & 15 & 29.4 & 35.7 & \\
\hline $\begin{array}{l}\text { Able to reduce opioid } \\
\text { medication? }\end{array}$ & & & & & & & 0.56 \\
\hline Strongly disagree & 4 & 4.7 & 44.4 & 5 & 9.8 & 55.6 & \\
\hline Disagree & 3 & 3.5 & 60.0 & 2 & 3.9 & 40.0 & \\
\hline $\begin{array}{l}\text { Neither agree nor } \\
\text { disagree }\end{array}$ & 28 & 32.9 & 57.1 & 21 & 41.2 & 42.9 & \\
\hline Agree & 24 & 28.2 & 68.6 & 11 & 21.6 & 31.4 & \\
\hline Strongly agree & 26 & 30.6 & 68.4 & 12 & 23.5 & 31.6 & \\
\hline
\end{tabular}

Notes: Explorative analysis was performed to compare perceived medication reduction between products containing CBD and CBD/THC. No significant difference was found for either pain medication or opioid medication reduction between groups. "Yes" and "No" answers were analyzed by Pearson's Chi-Square test. Descriptive data are presented as $N$ and percent replies per question (\%) either as \% within "contain THC" or \% within "reduce med".

harmful ["Disagree" (20.1\%), "Strongly disagree" $(54.8 \%)$ ], or can be addicting ["Disagree" (17.2\%), "Strongly disagree" (48.1\%)]. Additionally, participants report being more comfortable if $\mathrm{CBD}$ products would be prescribed and or dispensed by a doctor [prescribed: "Strongly Agree" (26.6\%), "Agree" (25.3\%), "Neither agree nor disagree" (32.1\%), "Disagree" (5.5\%), "Strongly disagree" (10.5\%)] [dispensed: "Strongly Agree" (21.1\%), "Agree“ (27.4\%), "Neither agree nor disagree“ (33.3\%), "Disagree“ (8.4\%), "Strongly disagree“ $(9.7 \%)]$.

\section{Discussion \\ Discussion of Data}

Taken together, participants report some perceived beneficial effects using CBM and CBD products including the reduction of pain medication. While the familiarity with dosing was mixed and participants used a wide variety of products including products containing $\mathrm{THC}$, they report that these products have helped them with many different pain-involving and neurological conditions. This finding is in alignment with similar reports describing CBD effects ranging from placebo-equivalent to highly effective. ${ }^{13}$ The effects of $\mathrm{CBM}$ and $\mathrm{CBD}$ on painful conditions seem to be context specific, with no effect on pain shown in patients with Crohn's disease, ${ }^{26}$ and pain-relieving effects reported for pain associated with Multiple Sclerosis, spinal cord injury, brachial plexus injury, limp amputation, ${ }^{27}$ peripheral neuropathy ${ }^{28}$ and fibromyalgia. ${ }^{29}$ This cohort also reported that products both with and without THC have helped them to reduce overall pain medication and more specifically opioid medication. The ability of CBD to significantly reduce opioid use and improve chronic pain has also been reported in an 8-week prospective cohort study in chronic pain patients published by Capano et al. ${ }^{30}$ In general, participants report a preference for obtaining products prescribed or recommended by their physician and to have the ability to access them in the doctor's office rather than from other sources.

Overall, our study describes the attitudes and experiences of the participants with CBM and CBD-containing products (medical cannabis) in a pain management clinic environment with a large Medicare and Medicaid patient population. The majority of participants are residents of 
Table 3 Knowledge, Opinions, and Interest

\begin{tabular}{|c|c|}
\hline \multicolumn{2}{|c|}{$\begin{array}{l}\text { Do you know if there is a difference between medical marijuana and CBD?, } \\
N(\%), N=24 \text { I }\end{array}$} \\
\hline No, there is no difference & $6(2.5)$ \\
\hline I do not know & $82(34.0)$ \\
\hline Yes, there is a difference & $153(63.5)$ \\
\hline \multicolumn{2}{|c|}{$\begin{array}{l}\text { If you have used CBD products in the past, are you familiar with how much } \\
\text { CBD is in the product you have used?, } N(\%), N=24 \text { I }\end{array}$} \\
\hline Extremely familiar & $34(14.1)$ \\
\hline Very familiar & $42(17.4)$ \\
\hline Somewhat familiar & $43(17.8)$ \\
\hline Not so familiar & $33(13.7)$ \\
\hline Not at all familiar & $15(6.2)$ \\
\hline I have not used CBD products & $74(30.7)$ \\
\hline \multicolumn{2}{|c|}{ I believe CBD is a good treatment option. $\mathrm{N}(\%), \mathrm{N}=239$} \\
\hline Strongly disagree & $8(3.3)$ \\
\hline Disagree & $3(1.3)$ \\
\hline Neither agree nor disagree & $58(24.3)$ \\
\hline Agree & $50(20.9)$ \\
\hline Strongly agree & $120(50.2)$ \\
\hline \multicolumn{2}{|c|}{ I believe CBD is harmful. $N(\%), N=239$} \\
\hline Strongly disagree & |3| (54.8) \\
\hline Disagree & $48(20.1)$ \\
\hline Neither agree nor disagree & $51(21.3)$ \\
\hline Agree & $4(1.7)$ \\
\hline Strongly agree & $5(2.1)$ \\
\hline \multicolumn{2}{|c|}{ I believe CBD can be addicting. $N(\%), N=239$} \\
\hline Strongly disagree & $115(48.1)$ \\
\hline Disagree & $41(17.2)$ \\
\hline Neither agree nor disagree & $76(31.8)$ \\
\hline Agree & $3(1.3)$ \\
\hline Strongly agree & $4(1.7)$ \\
\hline
\end{tabular}

If I were to consider using CBD, I would feel more comfortable if it was prescribed by a doctor. $\mathrm{N}(\%), \mathrm{N}=237$

\begin{tabular}{|l|l|}
\hline Strongly disagree & $25(10.5)$ \\
Disagree & $13(5.5)$ \\
Neither agree nor disagree & $76(32.1)$ \\
Agree & $60(25.3)$ \\
Strongly agree & $63(26.6)$ \\
\hline I would prefer to buy CBD products from my doctor over other sources \\
(smoke shops, dispensaries, internet). N (\%), N = 237 \\
\hline Strongly disagree & $23(9.7)$ \\
Disagree & $20(8.4)$ \\
Neither agree nor disagree & $79(33.3)$ \\
Agree & $65(27.4)$ \\
Strongly agree & $50(21.1)$ \\
\hline
\end{tabular}

Notes: About a third of Participants do not know if there is a difference between medical marijuana and $\mathrm{CBD}$ and a wide variety of responses exists regarding familiarity with CBD. At the same time, participants believed that CBD was a good treatment option, not harmful, and not addictive. About half of participants report that they would be more comfortable with their physician prescribing CBD products. Descriptive data are presented as $\mathrm{N}$ and percent replies per question (\%).
Riverside County, with a smaller amount from neighboring San Bernardino and San Diego Counties. The demographic representation of our cohort is in alignment with an anonymous survey distributed via social media that reported their sample of CBD users to be primarily white with a yearly household income of less than $\$ 25,000 .^{24}$ The data asking about participants awareness of CBD as a treatment option and efficacy (Supplemental Table 2) show that the majority of participants have had interactions with their peers, and to a lesser degree their providers talking about CBD. A similar response was observed in a survey among primary care patients, where only $18 \%$ describes their medical providers as being a good source for information regarding cannabis derived medications. ${ }^{31}$ When asked about their personal experience, $35.5 \%$ of participants have never tried a CBD product while those who have report trying several different products for multiple conditions. A majority described some positive effects of CBD products on their conditions and reduction of pain medication. It is important to mention that $36.5 \%$ of participants did not know or think that there is no difference between medical marijuana and CBD, further manifesting the criticism that we cannot say for certain which types of products were consumed. The survey question regarding the knowledge of CBD dosing showed that almost all answer choices were represented as similar percentages, suggesting that there is a high variability of familiarity with CBD content in CBD products. In a publication looking at the CBD concentration in a variety of products, one study shows inaccurate labeling of products in the majority of cases. ${ }^{3}$ The combination of variable familiarity and CBD concentration in available products puts patients in a difficult position when they are in search for a standardized CBD product to try as a therapeutic option. In addition, it is unknown if there was any THC present in the consumed products. Here, requirements for quality control and labeling for all hemp-based products being marketed would take the guesswork out of exact dosing and allow for better understanding of the products that patients may be accessing. This is particularly needed as there are no quality studies evaluating CBD dosing ranges for pain. Additionally, there is a need to evaluate differences between efficacy of CBD isolate products and whole plant extracts (limited to $<0.3 \%$ THC content - 84 FR 58522). Patients have a need to know the exact THC content of a product, as unregulated whole plant extracts may result in a positive drug test result. 


\section{Discussion of Current Literature Current Evidence for CBD and Pain}

When looking at the current literature, it is evident, that well-controlled studies investigating the effects of CBD on pain are currently not available. ${ }^{7}$ However, some literature is starting to investigate its effects. For example, a wellcontrolled study of purified CBD has demonstrated that CBD has low abuse potential, even within sensitive populations. ${ }^{32}$ In a preclinical study, CBD use has also been attributed to reducing drug-seeking behavior in mice. ${ }^{33}$ These positive results have brought up discussions about the role of CBD in combating the world's opioid epidemic. While studies have investigated the combined use of fentanyl with $\mathrm{CBD}$, the results were inconclusive and currently the impact of CBD on opioids is not known. ${ }^{7,34}$ Another recent study was investigating the role that CBD plays on craving behavior in abstinent individuals with heroin use disorder. ${ }^{35}$ This study shows that CBD doses (Epidiolex) of $400 \mathrm{mg}$ and $800 \mathrm{mg}$ were able reduce craving and anxiety induced by heroin's cues compared to placebo. However, while the CBD doses of $400 \mathrm{mg}$ and $800 \mathrm{mg}$ are relevant from a pharmacologic and therapeutic perspective, these doses vastly exceed the regularly commercially available hemp-CBD products which may present cost challenges as Epidiolex therapy is around $\$ 16,000 /$ year. ${ }^{34}$ Several manuscripts review the current state of knowledge and point out important questions. Specifically, could CBD have a role in addressing the national opioid crisis? ${ }^{10,11}$ Conversely, the data supporting THC as an analgesic and for opioid-sparing effects is more robust, specifically for neuropathic pain. ${ }^{36-39}$ The known benefit of THC for pain raises the question of whether the small THC component in some products was responsible for perceived analgesic effects and reduction of pain medications in our cohort, further highlighting the uncertainty of product content/potency consumed by respondents.

\section{Patients Perceptions}

Multiple surveys focusing on patients perspectives have been published. ${ }^{18,19,40-42}$ In the patient-focused surveys by Boehnke et al, improved quality of life, better side effect profile, improved pain and health, and decreased opioid use were reported among medical cannabis users. ${ }^{19,41,42}$ Both the reported improved pain and decreased opioid use show similarities with our reported findings for "CBD products", but these results need to be interpreted in the context of uncertainty regarding the $\mathrm{CBD} / \mathrm{THC}$ content of the products consumed by respondents of this survey. Additionally, participants in this cohort reported being able to reduce overall use of pain medication. A different survey reported that consumers are using $\mathrm{CBD}$ as a specific therapy for multiple different conditions including pain, anxiety, depression, and sleep disorders. ${ }^{40}$ In general, survey data emphasizes the need for controlled research investigating the potential use of $\mathrm{CBD}$ for a variety of conditions.

\section{Study Limitations}

This study has several limitations that need to be discussed. Regarding the demographics, the survey participants in this cohort are predominantly insured by Medicare or Medicaid and a limitation could be that this is not reflective of the general pain patient population and general population that is exposed to available CBD preparations. Additionally, terms like "CBD product", "Hemp", "Cannabis", "Medical Cannabis", "Medical Marijuana" that have been added to this manuscript and explained in the glossary were not well defined for the survey participants. One question in Table 1 ("Did any of the CBD products you used contain THC (the chemical that gets you "high"?") additionally needs clarification. With this question, we intended to ask participants if they distinguish between products that are sold as "CBD only" products and products that contain THC in higher percentages than $0.3 \%$. Since the verbiage does not clearly state this intent, the results of this question therefore need to be interpreted with caution. This survey was distributed in a pain clinic environment and was not limited to patients. We cannot exclude that family members or clinic staff participated in the survey. Also, the relatively small sample size $(n=253)$ is associated with bias (eg, a voluntary response bias) and may not be generalizable, particularly since only $70 \%$ have used a product. There are general limitations in a survey design, including non-sampling biases. $^{43}$ Additionally, there is the potential for recall bias, the representativeness of the sample, and the inherent uncertainty about what constitutes a "CBD product". Medical cannabis and cannabinoid products have been associated with a prominent placebo effect particularly important to keep in mind with self-reported benefits. ${ }^{44}$ Given these limitations, this is a well-described cohort demographically, and the data can be interpreted in this particular context. Voluntary surveys such as this one can help to identify areas for future more controlled research. 


\section{Conclusion}

Taken together, the opinions, beliefs, and experiences about and with $\mathrm{CBM}$ and CBD were predominantly positive in this cohort. Participants reported to be able to reduce overall pain and specifically opioid medication and would be more comfortable receiving CBD through prescription or purchase from their healthcare provider. It is now our responsibility as medical and scientific communities, working with the FDA, to produce welldesigned studies that can either support or disprove the anecdotes about cannabis and hemp by providing a stronger evidence-base for effectiveness in treating pain and other conditions, and continue to press for quality control of any product being consumed by patients.

\section{Glossary}

Cannabidiol (CBD) product - Any product that has a high $\mathrm{CBD}$, and "low or no" $(<0.3 \%)$ THC content. This nomenclature was used in our survey.

Cannabinoid Any substance that acts on the cannabinoid receptor system, both plant-derived and synthetic

Cannabis - A genus of plants with several species

CBD - Cannabidiol, a naturally occurring compound found in the Cannabis plant

CBM - Cannabis-based medicine

Hemp - The CBD-rich cannabis species containing less than $0.3 \%$ THC

Medical Cannabis/Marijuana - herbal drug derived from plants of the genus Cannabis containing $>0.3 \%$ of THC

THC - delta-9-tetrahydrocannabidiol

\section{Acknowledgments}

We would like to thank our clinic personnel in the Center of Excellence clinics of Desert Clinic Pain Institute and Summit Institute for their help and efforts in completing this study.

\section{Disclosure}

Vitamed Research, LLC. was supported by an unrestricted grant from Verséa ${ }^{\mathrm{TM}}$ Pharmaceuticals.

Dr Moeller-Bertram is Co-Founder and Chief Medical Officer for Verséa ${ }^{\mathrm{TM}}$ Pharmaceuticals. He also was supported by grants from Versea Holdings, LLC, during the conduct of the study.

Dr Backonja is a medical advisor as Medical Director for Verséa ${ }^{\mathrm{TM}}$ Pharmaceuticals.
Dr Wallace is a medical advisor for Verséa ${ }^{\mathrm{TM}}$ Pharmaceuticals.

Dr Michelle Sexton is a medical advisor for Verséa ${ }^{\mathrm{TM}}$ Pharmaceuticals and reports personal fees from Verséa ${ }^{\mathrm{TM}}$ Pharmaceuticals, outside the submitted work.

Dr Jan M Schilling reports grants from Verséa ${ }^{\mathrm{TM}}$ Pharmaceuticals, during the conduct of the study.

The authors report no other conflicts of interest in this work.

\section{References}

1. California health and safety code; 2017. Available from: https:// leginfo.legislature.ca.gov/faces/codes displaySection.xhtml? sectionNum $=11360 . \&$ lawCode $=$ HSC. Accessed January 27, 2020.

2. Merten JW, Gordon BT, King JL, Pappas C. Cannabidiol (CBD): perspectives from pinterest. Subst Use Misuse. 2020;55 (13):2213-2220. doi:10.1080/10826084.2020.1797808

3. Bonn-Miller MO, Loflin MJE, Thomas BF, Marcu JP, Hyke T, Vandrey R. Labeling accuracy of cannabidiol extracts sold online. JAMA. 2017;318(17):1708-1709. doi:10.1001/jama.2017.11909

4. Rubin R. Cannabidiol products are everywhere, but should people be using them? JAMA. 2019;322(22):2156. doi:10.1001/ jama.2019.17361

5. Fetterman PS, Turner CE. Constituents of Cannabis sativa L. I. Propyl homologs of cannabinoids from an Indian variant. $J$ Pharm Sci. 1972;61(9):1476-1477. doi:10.1002/jps.260061 0930

6. Adams R, Hunt M, Clark J. Structure of cannabidiol, a product isolated from the marihuana extract of Minnesota wild hemp. I. $J$ Am Chem Soc. 1940;62(1):196-200. doi:10.1021/ja01858a058

7. White CM. A review of human studies assessing cannabidiol's (CBD) therapeutic actions and potential. J Clin Pharmacol. 2019;59 (7):923-934. doi:10.1002/jcph.1387

8. Klotz KA, Schulze-Bonhage A, Antonio-Arce VS, Jacobs J. Cannabidiol for treatment of childhood epilepsy-a cross-sectional survey. Front Neurol. 2018;9:731. doi:10.3389/fneur.2018.00731

9. Sekar K, Pack A. Epidiolex as adjunct therapy for treatment of refractory epilepsy: a comprehensive review with a focus on adverse effects. F1000Res. 2019;8. doi:10.12688/f1000research.16515.1

10. Urits I, Borchart M, Hasegawa M, Kochanski J, Orhurhu V, Viswanath O. An update of current cannabis-based pharmaceuticals in pain medicine. Pain Ther. 2019;8(1):41-51. doi:10.1007/s40122019-0114-4

11. Piermarini C, Viswanath O. CBD as the new medicine in the pain provider's armamentarium. Pain Ther. 2019;8(1):157-158. doi:10.1007/s40122-019-0117-1

12. Mlost J, Bryk M, Starowicz K. Cannabidiol for pain treatment: focus on pharmacology and mechanism of action. Int $J$ Mol Sci. 2020;21:22. doi:10.3390/ijms21228870

13. Argueta DA, Ventura CM, Kiven S, Sagi V, Gupta K. A balanced approach for cannabidiol use in chronic pain. Front Pharmacol. 2020;11:561. doi:10.3389/fphar.2020.00561

14. Shannon S, Lewis N, Lee H, Hughes S. Cannabidiol in anxiety and sleep: a large case series. Perm J. 2019;23:18-041. doi:10.7812/TPP/ $18-041$

15. Linares IM, Zuardi AW, Pereira LC, et al. Cannabidiol presents an inverted U-shaped dose-response curve in a simulated public speaking test. Braz J Psychiatry. 2019;41(1):9-14. doi:10.1590/1516-44462017-0015 
16. van der Flier FE, Kwee CMB, Cath DC, et al. Cannabidiol enhancement of exposure therapy in treatment refractory patients with phobias: study protocol of a randomized controlled trial. $B M C$ Psychiatry. 2019;19(1):69. doi:10.1186/s12888-019-2022-x

17. Bradford AC, Bradford WD, Abraham A, Bagwell adams G. Association between US state medical cannabis laws and opioid prescribing in the medicare part D population. JAMA Intern Med. 2018;178(5):667-672. doi:10.1001/jamainternmed.2018.0266

18. Boehnke KF, Scott JR, Litinas E, Sisley S, Williams DA, Clauw DJ. Pills to pot: observational analyses of cannabis substitution among medical cannabis users with chronic pain. J Pain. 2019;20:830-841.

19. Boehnke KF, Litinas E, Clauw DJ. Medical cannabis use is associated with decreased opiate medication use in a retrospective cross-sectional survey of patients with chronic pain. $J$ Pain. 2016;17(6):739-744. doi:10.1016/j.jpain.2016.03.002

20. Shah A, Hayes CJ, Lakkad M, Martin BC. Impact of medical marijuana legalization on opioid use, chronic opioid use, and high-risk opioid use. J Gen Intern Med. 2019;34(8):1419-1426. doi:10.1007/ s11606-018-4782-2

21. Shi Y, Liang D, Bao Y, An R, Wallace MS, Grant I. Recreational marijuana legalization and prescription opioids received by Medicaid enrollees. Drug Alcohol Depend. 2019;194:13-19. doi:10.1016/j. drugalcdep.2018.09.016

22. Liang D, Bao Y, Wallace M, Grant I, Shi Y. Medical cannabis legalization and opioid prescriptions: evidence on US Medicaid enrollees during 1993-2014. Addiction. 2018;113(11):2060-2070. doi: $10.1111 /$ add. 14382

23. Philpot LM, Ebbert JO, Hurt RT. A survey of the attitudes, beliefs and knowledge about medical cannabis among primary care providers. BMC Fam Pract. 2019;20(1):17. doi:10.1186/s12875019-0906-y

24. Wheeler M, Merten JW, Gordon BT, Hamadi H. CBD (cannabidiol) product attitudes, knowledge, and use among young adults. Subst Use Misuse. 2020;55(7):1138-1145. doi:10.1080/10826084.20 20.1729201

25. Eysenbach G. Improving the quality of web surveys: the checklist for reporting results of internet E-surveys (CHERRIES). J Med Internet Res. 2004;6(3):e34. doi:10.2196/jmir.6.3.e34

26. Naftali T, Mechulam R, Lev LB, Konikoff FM. Cannabis for inflammatory bowel disease. Dig Dis. 2014;32(4):468-474. doi:10.1159/ 000358155

27. Wade DT, Robson P, House H, Makela P, Aram J. A preliminary controlled study to determine whether whole-plant cannabis extracts can improve intractable neurogenic symptoms. Clin Rehabil. 2003;17 (1):21-29. doi:10.1191/0269215503cr581oa

28. Xu DH, Cullen BD, Tang M, Fang Y. The effectiveness of topical cannabidiol oil in symptomatic relief of peripheral neuropathy of the lower extremities. Curr Pharm Biotechnol. 2020;21(5):390-402. doi:10.2174/1389201020666191202111534

29. van de Donk T, Niesters M, Kowal MA, Olofsen E, Dahan A, van Velzen M. An experimental randomized study on the analgesic effects of pharmaceutical-grade cannabis in chronic pain patients with fibromyalgia. Pain. 2019;160(4):860-869. doi:10.1097/j. pain.0000000000001464
30. Capano A, Weaver R, Burkman E. Evaluation of the effects of CBD hemp extract on opioid use and quality of life indicators in chronic pain patients: a prospective cohort study. Postgrad Med. 2020;132 (1):56-61. doi:10.1080/00325481.2019.1685298

31. Wershoven N, Kennedy AG, MacLean CD. Use and reported helpfulness of cannabinoids among primary care patients in vermont. $J$ Prim Care Community Health. 2020;11:2150132720946954. doi:10.1177/2150132720946954

32. Schoedel KA, Szeto I, Setnik B, et al. Abuse potential assessment of cannabidiol (CBD) in recreational polydrug users: a randomized, double-blind, controlled trial. Epilepsy Behav. 2018;88:162-171. doi:10.1016/j.yebeh.2018.07.027

33. Hay GL, Baracz SJ, Everett NA, et al. Cannabidiol treatment reduces the motivation to self-administer methamphetamine and methamphetamine-primed relapse in rats. $J$ Psychopharmacol. 2018;32(12):269881118799954. doi:10.1177/0269881118799954

34. Manini AF, Yiannoulos G, Bergamaschi MM, et al. Safety and pharmacokinetics of oral cannabidiol when administered concomitantly with intravenous fentanyl in humans. J Addict Med. 2015;9 (3):204-210. doi:10.1097/ADM.0000000000000118

35. Hurd YL, Spriggs S, Alishayev J, et al. Cannabidiol for the reduction of cue-induced craving and anxiety in drug-abstinent individuals with heroin use disorder: a double-blind randomized placebo-controlled trial. Am J Psychiatry. 2019;176(11):appiajp201918101191. doi:10.1176/appi.ajp.2019.18101191

36. Aviram J, Samuelly-Leichtag G Efficacy of cannabis-based medicines for pain management: a systematic review and meta-analysis of randomized controlled trials. 2017.

37. Hauser W, Fitzcharles MA, Radbruch L, Petzke F. Cannabinoids in pain management and palliative medicine. Dtsch Arztebl Int 2017;114(38):627-634. doi:10.3238/arztebl.2017.0627

38. Casey SL, Vaughan CW. Plant-based cannabinoids for the treatment of chronic neuropathic pain. Medicines. 2018;5:3. doi:10.3390/ medicines 5030067

39. Lee G, Grovey B, Furnish T, Wallace M. Medical cannabis for neuropathic pain. Curr Pain Headache Rep. 2018;22(1):8. doi:10.1007/s11916-018-0658-8

40. Corroon J, Phillips JA. A cross-sectional study of cannabidiol users. Cannabis Cannabinoid Res. 2018;3(1):152-161. doi:10.1089/ can.2018.0006

41. Sexton M, Cuttler C, Finnell JS, Mischley LK. A cross-sectional survey of medical cannabis users: patterns of use and perceived efficacy. Cannabis Cannabinoid Res. 2016;1(1):131-138. doi:10.1089/can.2016.0007

42. Corroon JM, Mischley LK, Sexton M. Cannabis as a substitute for prescription drugs - a cross-sectional study. $J$ Pain Res. 2017;10:989-998. doi:10.2147/JPR.S134330

43. Cheung KL, Ten Klooster PM, Smit C, de Vries H, Pieterse ME. The impact of non-response bias due to sampling in public health studies: a comparison of voluntary versus mandatory recruitment in a Dutch national survey on adolescent health. BMC Public Health. 2017;17 (1):276. doi:10.1186/s12889-017-4189-8

44. Gertsch J. The intricate influence of the placebo effect on medical cannabis and cannabinoids. Med Cannabis Cannabinoids. 2018;1 (1):60-64. doi:10.1159/000489291 


\section{Publish your work in this journal}

The Journal of Pain Research is an international, peer reviewed, open access, online journal that welcomes laboratory and clinical findings in the fields of pain research and the prevention and management of pain. Original research, reviews, symposium reports, hypothesis formation and commentaries are all considered for publication. The manuscript management system is completely online and includes a very quick and fair peer-review system, which is all easy to use. Visit http:// www.dovepress.com/testimonials.php to read real quotes from published authors.

Submit your manuscript here: https://www.dovepress.com/journal-of-pain-research-journal 